\title{
Influential Mentoring Practices for Navigating Challenges and Optimizing Learning During an Evaluation Internship Experience
}

\author{
Cheryl Poth \\ University of Alberta, Department of Educational Psychology, \\ Faculty of Education \\ Michelle Anderson-Draper \\ Alberta Children and Youth Services \\ Btissam El Hassar \\ University of Alberta, Department of Educational Psychology, \\ Faculty of Education
}

\begin{abstract}
The increased complexity of contexts that Canadian evaluators work in has important implications for evaluation education. Internship is a valued training component, yet what remains to be identified are empirically based quality indicators of the experience. Analyses of interviews with an intern, mentor, and coordinator supplemented by field notes revealed key features suggesting three influential mentoring practices: orientation to workplace context, autonomy of supervisory approach, and planning for evaluation agility. Implications for evaluation practice and evaluator induction are discussed in light of the Competencies for Canadian Evaluation Practice and three areas influenced by Dr. Lyn Shulha.
\end{abstract}

Keywords: evaluation internships, evaluation use, learning, mentors

Résumé : La complexité grandissante des contextes dans lesquels les évaluateurs canadiens travaillent a des conséquences importantes pour la formation en évaluation. Les stages sont une composante prisée de la formation, mais nous manquons encore d'indicateurs qui permettraient d'évaluer la qualité de cette expérience. Une analyse d'entrevues avec des stagiaires, mentors et coordonnateurs, complétée par des notes d’observation, révèle des caractéristiques clés qui suggèrent trois pratiques signifiantes de mentorat : l'orientation en contexte de travail, lautonomie au niveau de l'approche de supervision et l'anticipation du besoin d'adaptation de l'évaluation. Nous discutons des répercussions pour la pratique de lévaluation et pour l'initiation des évaluateurs au regard des compétences pour les évaluateurs canadiens et des trois domaines influencés par Mme Lyn Shulha.

Corresponding Author: Cheryl Poth, Centre for Research in Applied Measurement and Evaluation, Department of Educational Psychology, Faculty of Education, 6-110 Education North, University of Alberta, 11210 - 87 Ave., Edmonton, AB T6E 2G5; cpoth@ualberta.ca

() 2017 Canadian Journal of Program Evaluation / La Revue canadienne d'évaluation de programme 31.3 (Special Issue / Numéro spécial), 374-396 doi: 10.3138/cjpe.325 
Mots-clés : stages en évaluation, utilisation de l'évaluation, apprentissage, mentors

\section{INTRODUCTION AND BACKGROUND}

The mentoring practices advanced in this article are important for informing, planning, implementing, and assessing evaluator induction. Evaluator induction, also known as educational training for evaluators, varies considerably within the Canadian context and indeed around the globe (Dillman, 2013). In Canada evaluator induction ranges from learning on the job to a combination of coursework, internships, and advising - the latter often referred to in the literature as mentoring. The recent work of Rog (2015) points to the relationship between theory and practice to emphasize the need for learning opportunities of this integration describing "the important synergistic role between practice and theory in evaluation" (p. 223). Other research points to the essential learning afforded by practical experience, also called fieldwork or internships, for bridging evaluation theory from coursework and practice gleaned from observations (e.g., Cousins \& Aubry, 2006; LaVelle \& Donaldson, 2015). Considering the years of global discussion and debate related to the profession of evaluation, the lack of empirically derived guiding practices for bridging theoretical knowledge and practical skills is surprising (LaVelle \& Donaldson, 2010; Picciotto, 2011). This is especially true for novice evaluators, as noted by Dillman (2013), "While there are many articles that explore evaluator competencies or describe evaluation training programs, there is little empirical work explaining how novice evaluators acquire the competencies necessary to practice evaluation effectively" (p. 270). The mentoring practices in this article are intended to begin addressing the need for empirically based quality indicators of evaluation internship experiences within the Canadian context.

Our focus on the Canadian context reflects the distinctive history and practices of evaluation when compared with global counterparts (e.g., Buchanan, 2015; Poth, Lamarche, Yapp, Sulla, \& Chisamore, 2014). A pioneering influence on Canadian evaluation theory and practice has been Dr. Lyn Shulha. For more than two decades as a faculty member of Queen's University, Dr. Shulha has mentored over 75 graduate students-many of whom are installed as practitioners and scholars within the Canadian evaluation community. To honour Dr. Shulha's contribution, colleagues organized the Canadian Educational Evaluation Symposium: Exploring Past and Future Directions to Maximize Evaluation Use held on September 18, 2015. It was during this day that academic and community-based colleagues as well as past and present students had the opportunity to engage in critical conversations about fundamental and emerging issues in program evaluation in addition to highlighting Lyn's contributions and her influence on their work.

Under Dr. Shulha's tutelage, Cheryl Poth completed her doctoral program as a member of the newly established Assessment and Evaluation Group. Poth credits internship experiences as foundational for her development as a competent evaluator; this accomplishment has been externally corroborated by her ongoing 
work as a Credentialed Evaluator by the Canadian Evaluation Society (CES) - see evaluationcanada.ca for more information. During the application process for the Credentialed Evaluator designation, Poth articulated the impacts of the internships on her development of evaluation competencies across the five practice domains: reflective, technical, situational, management, and interpersonal. In the required narrative descriptions, she found herself linking the learning she experienced during the internships to aspects of the coursework she had completed and guidance she had received from her university-coordinator (i.e., Dr. Lyn Shulha) and organization-based mentors. These efforts inspired a pilot research project examining the effective features of a government-university evaluation internship experience from the perspectives of a student-intern, governmentmentor, and university-coordinator. Serendipitously, while writing up the analytic outcomes, Poth was invited to deliver remarks at the symposium to honour Dr. Shulha's influence on her former students. Following a struggle to communicate Dr. Shulha's multifaceted (and ongoing) influence on Poth's developmental journey as a university-based scholar, evaluator practitioner, classroom instructor, and academic advisor, Poth discussed how Dr. Shulha had modelled fostering stakeholder relationships, navigating new experiences, promoting evaluation use, and cultivating evaluation communities.

Returning home from the symposium, Poth began to consider, from her reflective remarks, the connections between the effective features revealed by the pilot study of internship experiences and Dr. Shulha's modelling influences. Poth discussed her view of Dr. Shulha's influence on how she approached mentoring with her own graduate student, Btissam El Hassar, who offered an additional perspective. What emerged was a comprehensive understanding of four mentoring practices with implications for informing planning, implementation, and assessment of evaluation induction. From their review of evaluation training literature, Poth and El Hassar realized the dearth of literature that captured the student experience of educational evaluation experiences. This finding was similar to what Dillman (2013) had recently reported: "little literature exploring how evaluation is learned from the perspective of the evaluation student or novice evaluator" (pp. 271-272). The balance of this article tells our story, organized into four sections. First, we elaborate the rationale for an examination of internship experiences within the Canadian context and then describe the empirical process we used to identify effective features. These details include background about who was involved and how the internship was conceived and implemented, followed by description of data collection and analysis procedures. Second, we describe the effective features emergent from the analysis and then discuss the links among influential mentoring practices generated by the features and the practice competencies identified by the CES. Third, we infer Dr. Shulha's influences to Canadian evaluation theory and practice, which is a common theme among the articles in this special issue. The article forwards study implications to Canadian evaluation theory and practice, specifically informing evaluator induction. Finally, we present the study limitations and future directions for research aimed at preparing 
competent evaluators for the complex contexts in which they will be expected to work.

\section{EVALUATION NEEDS AND OPPORTUNITIES WITHIN THE CANADIAN CONTEXT}

The field of evaluation in Canada is shifting as government-based managers become more aware of the need for rigorous evaluations and the increased demand for evaluators who can meet their informational needs (Gauthier et al., 2010). Accessing evaluation expertise has become a pressing issue for many government ministries as evaluation has become increasingly embedded within organizational work (e.g., Gauthier, Kishchuk, Borys \& Roy, 2006; Government of Canada, 2009). A shortage of competent evaluators suggests that government should consider new ways of accessing and recruiting those with evaluation expertise and/or formal professional evaluation designations. Most recently, the Canadian government introduced a Directive on Results (Government of Canada, 2016) defining their standard for evaluation. The emphasis in the directive is on ensuring departmental evaluators develop their competencies and earn evaluation-related designations (see 4.4 .12 of the Directive at http://www.tbs-sct.gc.ca/pol/doc-eng. aspx?id=31306). Such endeavours may enhance demand for training opportunities, recruitment of staff with previous evaluation experience in a government context (such as an internship), and an increase in the number of applications for professional designation of Credentialed Evaluator.

The launch of the Credentialed Evaluator designation in 2010 was pivotal for the Canadian evaluation profession as one of several approaches for quality assurance (Schwartz \& Mayne, 2005). The designation intends to "define, recognize, and promote the practice of ethical, high quality, and competent evaluation in Canada through a program for professional designations" (CES website, www. evaluationcanada.ca). To gain the designation, evaluators must present evidence of a graduate-level degree or certificate, evidence of two years' evaluation-related work experience within the past 10 years, and education and/or experience related to $70 \%$ of the competencies in each of five competency domains: reflective, technical, situational, management, and interpersonal (see Table 1). Developed through an intensive consultative process that included member consultations and expert validation processes, the competencies are defined as "the background, knowledge, skills, and dispositions program evaluators need to achieve standards that constitute sound evaluations" (CES website, www.evaluationcanada.ca). As of August 8, 2016, there are 324 credentialed evaluators through this program (CES website, http://evaluationcanada.ca/roster-credentialed-evaluators). Among the challenges for Canadian evaluators, in contrast to our counterparts in the United States, is the existence of very few formal training programs at the graduate level of education specifically devoted to evaluation (Gauthier et al., 2004; Gauthier et al., 2010). Furthermore, there is a call to increase our knowledge of evaluation professional development within a government context. Specifically, the evaluation of 
Table 1. Summary of Competencies for Canadian Evaluation practice

\begin{tabular}{lll}
\hline $\begin{array}{l}\text { Competency } \\
\text { domain }\end{array}$ & Focus & $\begin{array}{l}\text { Number of } \\
\text { competencies }\end{array}$ \\
\hline Reflective practice & $\begin{array}{l}\text { Fundamental norms and values under- } \\
\text { lying evaluation practice and awareness } \\
\text { of one's evaluation expertise and needs } \\
\text { for growth. } \\
\text { Specialized aspects of evaluation, such as } \\
\text { design, data collection, analysis, inter- } \\
\text { pretation, and reporting. } \\
\text { Technical practice }\end{array}$ & 76 \\
Situational practice & $\begin{array}{l}\text { Application of evaluative thinking in } \\
\text { analyzing and attending to the unique } \\
\text { interests, issues, and contextual circum- } \\
\text { stances in which evaluation skills are } \\
\text { being applied. } \\
\text { Process of managing a project/evalua- } \\
\text { tion, such as budgeting, coordinating } \\
\text { resources, and supervising. } \\
\text { People skills, such as communication, } \\
\text { management }\end{array}$ & 7 \\
negotiation, conflict resolution, \\
Interpersonal \\
practice
\end{tabular}

Source: Canadian Evaluation Society (2010)

CES's Professional Designation Program suggests efforts are warranted to enhance our understanding of the alignment between evaluation professional development offered and CES competencies, especially as it relates to public servants (Fierro, Galport, Hunt, Codd, \& Donaldson, 2016).

The educational landscape changed with the establishment of the Consortium of Universities for Evaluation Education in 2008 as "a collaborative partnership among universities, government, and the Canadian Evaluation Society ... for the purpose of building capacity in graduate-level education and training in Canada" (Consortium of Universities for Evaluation Education website, www. evaluationeducation.ca). Common across certificates in program evaluation and graduate degrees is the inclusion of internship experiences of varying duration and timing with the programs. Formalized internship structures offer collaborative opportunities between universities and governments (Cousins \& Aubry, 2006; Cousins et al., 2006; Gauthier et al., 2004). These internship experiences can have several benefits: for the intern, the experience can be counted toward the evaluation-related work experience requirement for the Credentialed Evaluator designation; for government, the experience can provide access to a pool of 
competent candidates; for the university, an enhanced reputation and assistance in maintaining relevant curriculum. Thus it may be surprising that even though such collaborative efforts can be mutually beneficial, they appear to be limited in their offerings.

Internship experiences are not unique to the evaluation field. Other fields such as medicine, clinical psychology, and teacher education require field-based experiences in the contexts in which they will be expected to work, like classrooms and clinics. Dillman (2013) makes an important distinction between those fields and that of evaluation because of the requirement for successful completion of the experience as assessed by standards set out by professional bodies (e.g., Canadian Psychological Association, 2016). Common across these experiences is the intent to provide opportunities for diverse learnings and application of skills that are less structured than in the classroom. For example, Dillman (2013) found mentoring and field experiences to be considered participants' "most significant learning experiences" even though fewer had the opportunity to engage in the former (53\% vs $75 \%$ of the 179 survey respondents). Similarly, in a study of related to the field of industrial engineering and management, internship experiences were found to offer students the opportunity to apply their learned skills, improve their soft skills (e.g., communication) by working in a team, and potentially help their integration in the labour market (Amorin, Pimentel, \& Rosa, 2012). In nursing, for example, mentoring is found to be an effective strategy to prepare novice nurse practitioners to deal with the internal and external stressors associated with the profession (Hill \& Sawatzky, 2011).

Across different fields, in addition to allowing trainees to practice their skills, internships provide them the opportunity to explore their career paths and preferences based on a realistic understanding (Callanan \& Benzing, 2004). In a review of the literature on the role of internships, Callanan and Benzing (2004) reported on studies that identified internships' positive impact on job satisfaction, job stability, and perception of job fit. Indeed, the most consequential activity improving students' ability to secure an employment position was found to be completion of an internship. These findings are consistent with recent studies (e.g., Gault, Leach, \& Duey, 2010; Thune \& Støren, 2015) representative of diverse programs (e.g., science and technology, business and administration, social sciences). Field experience in cross programs was reported to provide students practical skills, realistic expectations of job tasks, opportunities to network, and a transition from school to work life (Thune \& Støren, 2015), and increase their employability (Gault et al., 2010). While internships can be important to students' learning, the extent of their value is contingent on other factors such as the length of the experience (Dillman, 2013; Thune \& Støren, 2015).

Quality of the internship experience is important because the provision of any experiential learning opportunity does not necessarily guarantee a meaningful learning experience for the intern. Research on evaluator competencies is scarce, and such research has typically been theoretical in focus and limited to identifying needed competencies (e.g., Jacob \& Boisvert, 2010; Wilcox \& King, 
2014). What remains to be empirically examined is an internship experience in situ, and documenting the interactions including activities, challenges, and learning outcomes to gain an understanding of the key features for preparing competent evaluators.

\section{THE INTERNSHIP RESEARCH PROJECT}

\section{Background}

The internship was initially conceptualized from informal conversations between the mentor (Anderson-Draper) and coordinator (Poth) related to their mutual interest in building evaluation capacity and providing opportunities for real-world learning experiences. At the time, the mentor, also a Credentialed Evaluator, held a provincial government management position focused on evaluation, and the coordinator was a faculty member with an agenda for establishing an evaluator induction program. The mentor described the stimulus for creating the internship opportunity as being the pressing need for trained evaluators within government, saying:

We ... worked with the university in order to fill and identify a need we had at the ministry level to have some work done on two specific projects and also because I have a professional commitment to support students. It helped the ministry in terms of building relationships with the university and having a student as part of our Policy Branch.

At the encouragement of her supervisor, the mentor invited the universitybased coordinator and a designated second-year master's student to an initial meeting to explore the possibility of a summer internship. The potential intern's background and goals-including previous work experience in the health field and completion of an advanced quantitative research methods course, as well as registration for the subsequent term in an evaluation-focused graduate coursewas seen as a good fit for contributing to two projects during the four-month summer internship (May to August). The intern's graduate program did not require an internship experience, although it was strongly encouraged and facilitated by faculty, which resulted in students seeking and completing at least one such experience during their program.

The first project involved the analysis of survey data from an outcomes evaluation of a mediation program and would likely require the intern to work alongside the program manager in preparing a final report for the provincial committee. The second project required conducting a literature review to inform the development of a readiness assessment tool that would be used for an implementation evaluation of a new initiative for Children's Services. For the latter, the process was expected to be collaborative and iterative, with each stage of development vetted by a panel of stakeholders. At the end of the project, the tool would be presented to the stakeholders orally and a written product shared. Common 
across both projects was the anticipated need for the intern to work with the government mentor, her evaluation-focused team, and additional organizational members.

The internship was conceptualized so that the intern would be based out of the government office where the mentor would provide day-to-day support. The coordinator also agreed to provide a secondary source of support with a focus on performing an external review of the internee's reports before final submission to the mentor. Formal meetings among the three (intern, mentor, and coordinator) were scheduled at three points (initial, midway, and post) and supplemented with informal meetings between the mentor and intern as well as between the coordinator and intern as needed. The initial meeting helped to familiarize the mentor with the skills of the university participants, while it also served to inform the university participants of the government's expectations for the internship. The midway meeting provided an opportunity to discuss how the internship was progressing and to provide informal feedback to one another. The post meeting was focused on reflecting and identifying the challenges and successes of the internship experience.

\section{Data Collection and Analysis Procedures}

The study integrated two data sources: interviews and field notes. Interviews afford an excellent means of accessing the perspectives of participants (Brinkmann \& Kvale, 2015; Patton, 2015). Field notes are useful for complementing what participants share during interviews by documenting researcher observations and interpretations of the physical setting and social environment created by the way people interact (Marshall \& Rossman, 2015; Patton, 2015). Following receipt of ethical approval by their Institutional Review Board, research assistants not involved in the internship led the data collection and initial data analysis. Individual semistructured, in-depth interviews with the intern, mentor, and coordinator were conducted following the completion of the internship. Field notes were taken following each interview, and the research assistant expanded the details in these notes within 24 hours.

Each interview followed a similar protocol of questions adapted to each role focused on generating understandings across four areas: (a) Assess skill development during the internship. What evidence can you describe related to you/the intern's development of particular skills within the Competencies for Canadian Evaluation Practice? (CES, 2010) (b) Identify key internship activities. What opportunities were made available to you/the intern that impacted your experience? (c) Consider the affective and cognitive effects of the internship. What impact, if any, did the internship experience have on your thinking about the evaluation profession as distinct from research and/or evaluation practice? (d) Discuss suggestions for future internships. What changes would you make to the internship experience and why? The hour-long interviews were audio-recorded and transcribed verbatim. The interview transcriptions were uploaded into Atlas-ti, and the analyses were undertaken. 
The analyses involved four steps. First, an inductive approach was used to generate understandings of the internship experience from each perspective using a constant comparison approach (Glaser \& Strauss, 1967). To do this, each transcript was analyzed separately, and unique code lists with preliminary definitions were developed by Poth and a research assistant. A second research assistant independently reviewed these lists and interrater reliability was assessed. Any discrepancies were discussed, definitions refined, and summaries were created and distributed to participants with the invitation to provide feedback related to accuracy. Throughout the data collection and analysis process, theoretical memos captured the development of ideas, concepts, and understandings (Grbich, 2013). Second, a cross-perspective comparison was undertaken to reveal similarities and differences among the three interview transcripts. The code lists were compared, and then summaries were generated pertaining to each part of the protocol: skills gained during the internship, activities undertaken during the internship, affective and cognitive effects, and suggestions for future internships. Third, information gleaned from the field notes was integrated into these descriptions and reviewed by Anderson-Draper, and the summaries were shared with the interview participants. Finally, Poth linked her experience with Dr. Shulha to the findings, then together Poth and El Hassar applied their perspective of their work together to the findings, and Poth extrapolated to Dr. Shulha's contributions to the literature. The discussion points emerged from the integration of the interpretations of findings in light of all the authors' experiences as involved in the internship experience and as being influenced by Dr. Shulha's mentoring.

Five strategies enhanced the reliability of the data collected and validity of the data interpretations: (a) use of theoretical memos to capture emerging understandings during data collection and analysis, (b) use of multiple coders during the analysis to promote intercoder reliability, (c) member checking the preliminary data interpretations with participants for errors or omissions, (d) data triangulation from multiple perspectives including the intern, mentor, and coordinator, and (e) methodological triangulation of interviews with field notes (Grbich, 2013; Patton, 2015).

\section{FINDINGS}

The integrated analysis revealed three effective features of the internship experience that provide the organizational structure for the section: attending to organizational belonging, promoting self-directed learning, and responding to changing circumstances. For each feature, a description of the experience including key activities, emergent challenges, and final outcomes is provided.

\section{Attending to Organizational Belonging}

A formal introduction familiarizing organizational members to the intern's skills and the assigned workspace was important for helping her to get started. Several examples were offered by the intern about how the mentor facilitated the intern's 
contribution and encouraged the intern's participation by describing her skills to the other team members and asking for her opinion during team meetings. The intern portrayed the workspace assigned to her as being conducive to performing her assigned duties: "I had a workspace. I had the ideal statistics work desk with my double screens and they were really ... keen on making it so that I had everything that I needed when I got there, which was awesome." These efforts indicated to the intern that her contribution was valued, because she warranted an introduction and workspace allocation.

The intern described difficulties with recognizing organizational expectations related to physical presence in the workplace. She described her process of adapting to new organizational norms because "missteps required me to confront my assumptions and adjust to the new organizational expectations." She attributed her blunders to the differences between the academic and her previous workplace environments with the internship environment. The intern recalled a meeting with the mentor after the third week of the internship where she explicitly explained the need for the intern to be physically present during work hours. The intern acknowledged that there had been an initial discussion about being physically present in the government office during her allotted time, yet she had assumed, based on her previous experiences, that working from home would be acceptable.

The tension had escalated when the intern did not appear in the office when expected with an impending deadline. The mentor described the resulting anxiety:

it was a critical time ... we just needed to be together and this is such a short-term piece, the work needs to get done ... because it's summer and when I'm available, the intern needed to be there too, when we agreed that she would be.

Following the discussion, the intern was physically present in the office for the remaining duration of the internship, and both the mentor and coordinator acknowledged the need for initial discussions and contracts to clearly specify expectations of physical presence.

At the end of the internship, there was consensus across the perspectives that the intern had successfully navigated entry as a valued member of the team and had developed essential people skills related to communication and collaboration. The mentor pointed to the unique contributions the intern offered the team:

The work that we had set up to do, that I had hoped the student could contribute to, she was able to do that and brought some good skills, quantitative skills, that she was able to bring and share. ... I guess I say that it's successful because in my mind, what we had set out to do, we achieved those objectives.

The intern depicted the team environment as being collaborative and welcoming to the ideas she communicated. The intern also spoke of the need for negotiating clear understandings of expectations upfront and addressing emergent workplace conflicts to become familiar with organizational norms of behaviour. 


\section{Promoting Self-Directed Learning}

The internship experience was characterized by a degree of autonomy evidenced by the shared expectation that the intern would work independently on tasks and that the mentor and coordinator would be available for ad hoc consultation. Frequent interactions initially provided the intern with sufficient opportunities for verifying her work and helping her identify next steps in completing new tasks. As the internship progressed, the interactions decreased in frequency over time to those that were scheduled ahead of time, due to time constraints on the part of everyone involved. Further, the mentor noted that this was how she typically worked with new employees, saying, "the intern was not micromanaged and experienced autonomy that would be expected of her if she were an employee." The intern noted the usefulness of meetings with the mentor and her desire for these to occur more frequently: "I definitely wished at times that there were more regularly scheduled meetings ... I definitely felt like I could have used more time with her." The intern described needing more guidance than what was often provided, and even though she reported having observed other team members requesting meetings with the mentor, she described being hesitant to do the same.

A similar problem emerged related to the heightened expectations on the part of the intern for the coordinator to facilitate their interactions. The intern noted the benefit of structured access to the coordinator's expertise for building confidence, yet had the intern not sought the coordinator's assistance:

I don't know anything! Come on! So it was really overwhelming to be looked to as an expert. And I know that's what we're learning as graduate students and that's all part of the experience but, just having that extra ... knowing that you have that backup, is so important.

The coordinator reported that, without hearing anything different, she had assumed the intern was receiving adequate guidance from the mentor and her team. The coordinator displayed surprise upon hearing that this had not always been the case, even though she had initially offered to meet with the intern as needed. The intern described that working with others on tasks would have helped her to be better positioned for taking on the new evaluation-specific tasks.

The intern described the challenges she experienced and the resulting eventual rewards from struggling through the learning process that occurred when tasked to independently write a report based on quantitative data analysis she had completed related to the first project (see internship background). The intern reported discovering that her expertise was limited to analysis procedures, and new skills were required to complete the interpretation and report. Although the intern characterized the overall experience as positive, it was also stressful: "it was a learning curve. It was crazy. And, it was good but, you know, I think there were a lot of lessons we learned about what work can be expected." At the time, neither the mentor nor the project manager had been available. Without access to someone to help her, the intern sought guidance from other resources and used 
examples such as a template to figure it out by herself. The intern talked about her process as considering who would be the audience for the report, what the audience would want to know, and how the audience might use the interpretations. The intern described her surprise that she was able to do so on her own, and described the experience as helping her become more self-sufficient when faced with learning new skills.

Opportunities for networking with others working in the area of evaluation contributed to the intern becoming familiar with the range of functions of an evaluator. Several examples included participating in seminars with those involved in a government evaluation network and the Canadian Evaluation Society. All participants agreed that the mentor had tried to facilitate the intern's participation in professional development opportunities during the internship, but that the lack of time impeded the intern's ability to participate as desired and initially planned. To that end, the mentor noted that an internship of longer duration with a greater number of hours allotted per week would increase an intern's ability to participate along with completing their assigned work. One opportunity that was realized was that the mentor, intern, and coordinator co-presented at the annual CES conference the following year.

At the end of the internship, there was agreement that the intern demonstrated interpretation and reporting skills that were valued by team members. The mentor described the unique role of the intern within her team as someone who could provide interpreting guidance and whose expertise was routinely sought. The mentor also pointed to the need for gaining an understanding of the intern's strengths and learning needs, and allocating time to support these areas of professional learning as critical. The intern admitted that she was responsible for pinpointing the areas of evaluation-specific skills in need of further professional development and needed to work on self-directing her learning process by asking for time to meet with the mentor.

\section{Responding to Changing Circumstances}

The intern recalled her participation in an initial planning meeting as helpful for being able to respond appropriately to changing circumstances within the evaluation projects. It was during this meeting that an individualized work plan for the intern was developed and communicated to team members. Furthermore, the intern recounted the planning meeting as essential for acquainting her with the various team projects and specifically how her work fit within the larger evaluation team's efforts and goals.

The intern's individualized work plan stipulated involvement in tasks across two different projects. The mentor reported having chosen projects that had specific timelines and deliverables that were to be completed within the summer timeframe and anticipated drawing on the intern's existing research skills (see internship background for further details). Only later did the intern realize that her cross-project tasks meant that as progress on one project was stalled, she could shift her focus to the other project, thus enabling the projects to continue in a 
timely manner. The intern described the mentor's accurate prediction that each of the projects would be delayed by the absence of stakeholders and evaluation team members due to summer vacations. The mentor explained her cross-project strategy:

It was just sort of really busy, and it might have been nice to just focus on one of the several distinct projects. But the problem with that is, things stop and start and, especially during the summer, some of the key stakeholders that need to be engaged in some of this work are gone for a couple of weeks. So, it probably was not even feasible to say, "Just focus on that," because there were gaps in time.

An emergent advantage for the intern described by all three perspectives was the increased exposure to working with different stakeholders across multiple projects.

The intern reported learning a great deal from the mentor about how much time and energy she should be spending working with stakeholders. The intern sought the mentor's guidance in response to what the intern described as "enormous time and energy invested" when working with stakeholders. She specifically referred to her work on the second project when tasked with facilitating discussions among stakeholders that the intern described as "endless and uninformative." The mentor recounted counselling the intern that part of her facilitative role was to monitor the stakeholders' emerging informational needs for the evaluation. The intern described having reviewed the survey results with stakeholders and facilitating the application of results for informing program improvements. The mentor commented on the unique learning opportunity afforded by the two projects because it required constant vigilance about the extent to which stakeholders were engaged.

Throughout the internship, evidence emerged attesting to inconsistency between the tasks stipulated by the work plan and the time allotted during the internship to complete them. Specifically, the intern described learning to balance between responding to emerging stakeholders' needs and reinforcing the boundaries of a contract: "I'm saying no. That's outside of the bounds of what we've agreed on, and there's no time." The intern described the work as being time-intensive to the extent that it went beyond her allotted time. When the intern approached the coordinator for help bounding her role within the projects, the coordinator reported that she supported the intern and described the learning she hoped the intern had experienced:

We want to teach our students to be mindful if they're committed to certain hours a week, to do that kind of time. We want to protect our students, but then we also want to-and I don't know how to instill [this] yet in students-sometimes when you're getting something special out of it, you put a little more time into stuff because you know that they're putting time into it. Not to the extent that they [students] get taken advantage of, but you know, a couple of extra hours here or there is what's expected in the workplace, without getting overtime. 
Across the perspectives, there was agreement that the intern had successfully adapted her work plan to meet the emergent needs of the stakeholders. Even though the mentor agreed that focusing on a single project would likely be easier, realistically this might not be possible nor would it reflect a real-world evaluation experience. The intern described the learning process related to prioritizing the needs of stakeholders with the tasks that would contribute to meeting these needs. This in turn allowed her to bound her work and respond appropriately to requests from both colleagues and stakeholders as circumstances and priorities changed.

\section{DISCUSSION}

The study findings point to three influential mentoring practices for discussion: orientation to workplace context, autonomy of supervisory approach, and foundation for evaluation agility (see Table 2 for summary). For each mentoring practice, we link our study findings to the literature as well as to Dr. Shulha's influence in the field of evaluation.

Table 2. Influential Mentoring Practices Emergent from the Internship Experience

\begin{tabular}{|c|c|c|c|}
\hline $\begin{array}{l}\text { Mentoring } \\
\text { practices }\end{array}$ & $\begin{array}{l}\text { Orientation to } \\
\text { workplace context }\end{array}$ & $\begin{array}{l}\text { Autonomy of } \\
\text { supervisory ap- } \\
\text { proach }\end{array}$ & $\begin{array}{l}\text { Foundation for } \\
\text { evaluation agility }\end{array}$ \\
\hline Effective features & $\begin{array}{l}\text { Attending to organ- } \\
\text { izational belonging }\end{array}$ & $\begin{array}{l}\text { Promoting self- } \\
\text { directed learning }\end{array}$ & $\begin{array}{l}\text { Responding to } \\
\text { changing circum- } \\
\text { stances }\end{array}$ \\
\hline Key activities & $\begin{array}{l}\text { Formal introduc- } \\
\text { tion, encouraging } \\
\text { participation, and } \\
\text { assigning workspace }\end{array}$ & $\begin{array}{l}\text { Scheduled meet- } \\
\text { ings, individualized } \\
\text { tasks, and network- } \\
\text { ing with others }\end{array}$ & $\begin{array}{l}\text { Development of } \\
\text { work plan and } \\
\text { participation in } \\
\text { planning meeting }\end{array}$ \\
\hline $\begin{array}{l}\text { Emergent } \\
\text { challenges }\end{array}$ & $\begin{array}{l}\text { Making explicit } \\
\text { organizational } \\
\text { expectations }\end{array}$ & $\begin{array}{l}\text { Allocating time for } \\
\text { professional skills } \\
\text { development }\end{array}$ & $\begin{array}{l}\text { Negotiating work } \\
\text { boundary with } \\
\text { stakeholders }\end{array}$ \\
\hline Final outcomes & $\begin{array}{l}\text { Successful entry, } \\
\text { building effective } \\
\text { relationships, and } \\
\text { valued team role }\end{array}$ & $\begin{array}{l}\text { Expertise sought by } \\
\text { team and increased } \\
\text { self- sufficiency }\end{array}$ & $\begin{array}{l}\text { Adapted work plan } \\
\text { to stakeholder } \\
\text { needs and priorities }\end{array}$ \\
\hline Developingskills & $\begin{array}{l}\text { People skills: } \\
\text { Collaboration and } \\
\text { communication }\end{array}$ & $\begin{array}{l}\text { Specialized } \\
\text { technical skills: } \\
\text { Interpretation and } \\
\text { reporting }\end{array}$ & $\begin{array}{l}\text { Evaluative thinking } \\
\text { skills: Evaluation } \\
\text { use and contexts }\end{array}$ \\
\hline Futureskills & $\begin{array}{l}\text { Negotiating expecta- } \\
\text { tions and addressing } \\
\text { conflicts with others }\end{array}$ & $\begin{array}{l}\text { Recognizing areas in } \\
\text { need of assistance } \\
\text { and requesting help }\end{array}$ & $\begin{array}{l}\text { Attending to needs } \\
\text { of stakeholders } \\
\text { and responding } \\
\text { appropriately }\end{array}$ \\
\hline
\end{tabular}




\section{Orientation to Workplace Context}

The orientation efforts on the part of the mentor and coordinator (i.e., formal introduction, encouraging participation, and assigning workspace) were noted as having an enduring impact on the intern's experience and learning outcomes. As the intern navigated organizational entry and ultimately played a valued role within the team, the findings revealed evidence of developing people skills (i.e., collaboration and communication) associated with the domain of interpersonal practice competencies (CES, 2010). At the same time, the intern identified additional people skills in need of further development related to negotiating expectations and resolving conflicts in the workplace. Attention to people skills contributed to the intern's understanding of how to go about establishing and sustaining effective relationships. Such roles are aligned with literature pointing to the roles of the mentor and coordinator in effective internships as not only introducing the intern but also supporting the intern's management and mitigation of problems as they emerge in the area of Information System Technology (Henry, Rehwaldt, \& Vineyard, 2001). This is consistent with other fields such as Industrial Engineering and Management that require teamwork within a complex work environment (Amorin et al., 2012). Practicum experiences are generally found to help students transition from school to work expectations, increasing their likelihood of success in their professional life (Callanan \& Benzing, 2004; Gault et al., 2010; Thune \& Støren, 2015).

Poth attributes the central role of relationships in her mentoring approach to her experiences establishing relationships with stakeholders during her internships. She recalls being encouraged to help with a children's activity during a particular evaluation within the early childhood context in an effort to navigate entry into the context. This approach was influenced by Poth's experiences as a member of the Assessment and Evaluation Group because Dr. Shulha encouraged active participation in the projects to cultivate a sense of belonging within the evaluation context in addition to the group. In Poth's subsequent work as a cofounder of the Alberta Clinical and Community Based Evaluation and Research Team, she employs strategies similar to what she experienced as a member of the Assessment and Evaluation Group. In so doing, she encourages graduate students to establish their own relationship with stakeholders with the intent to develop a sense of belonging within the team and projects using such activities as attending stakeholder meetings on their own. El Hassar recounts her experience of joining one ongoing project as a new member of Poth's research team and being welcomed and tasked with key activities that required learning new skills. When El Hassar needed assistance, the other students and Poth supported her learning in an environment where she did not feel herself a burden. During El Hassar's work on another project requiring close stakeholder relationships, she was mentored to take increased responsibility gradually, beginning with attending stakeholder meetings, then being tasked with interacting with stakeholders, and eventually to becoming the project lead. In so doing, Poth's mentoring approach, similar to Dr. Shulha's, reflects recent theories of learning such as those described by Eames 
and Coll (2012): "Learning can be viewed as occurring through participation in socially and culturally determined activity, which leads to a gradual enculturation of the student into the community of practice" (p. 1).

Similar to the results of the mentor's orientation efforts in the present study, Dr. Shulha's work has contributed to our understandings of the conditions for effective collaborations within evaluation teams and approaches. The models advanced by Shulha and Wilson (2003) provided early guidance for collaborative mixed methods evaluation teams. These models classify teams along a continuum (i.e., distanced, related, and integrated) according to their motivation for involvement, depth of participation, quality of dialogue, authority for decision making, and meaning making. More recently, Dr. Shulha's career-spanning work in collaborative approaches in evaluation has culminated in a set of evidence-based principles for guiding "evaluation practice in contexts where evaluation knowledge is collaboratively produced by evaluators and stakeholders" (Shulha, Whitmore, Cousins, Gilbert, \& al Hudib, 2016, p. 1). Because of the well-recognized impacts of participatory, collaborative, and stakeholder-oriented approaches on use (e.g., Cousins \& Earl, 1992; King, 2007; O'Sullivan, 2012), this work has the strong potential for informing evaluation practice in the years to come.

\section{Autonomy of Supervisory Approach}

The supervisory approach on the part of the mentor and coordinator (i.e., scheduled meetings, inviting requests for help, and individualized tasks) created an internship experience similar to that of a regular employee. As the intern worked independently and recognized the need for seeking guidance, the findings disclosed evidence of developing new specialized skills (i.e., interpretation and reporting) associated with the domain of technical practice competencies (CES, 2010) as well as having applied existing skills to new evaluation contexts (i.e., quantitative data analysis). The autonomous yet guided quality of the mentoring practice supported the intern's navigation of self-sufficiency as she learned how to go about recognizing areas in need of assistance and overcoming discomfort when learning new skills. This type of practice is aligned with the scaffolding approach well known as Vygotsky's "zone of proximal development" (Cain, 2010). Providing a challenging yet nurturing environment aligns with other research about internships in various fields that points to effective work-based educational experiences (e.g., Henry et al., 2001; Yiu \& Law, 2012). In science and technology fields, research found that these field experiences helped interns integrate the skills learned in the classroom with those in the practicum (Eames \& Coll, 2012).

Poth points to Dr. Shulha's tasking her with significant responsibilities during internships as key learning experiences that helped her navigate new experiences. In so doing, Poth recounts having to independently learn new evaluation-focused skills and at the same time beginning to conceive innovative evaluation practices. The result of such thoughtful and collaborative learning efforts have been meaningful contributions to the evaluation literature by Dr. Shulha's former students, which would not have been possible without her careful mentorship (e.g., Poth \& Shulha, 
2008; Van Melle, Cimellaro, \& Shulha, 2003). In the same way, Poth has adopted similar practices with her own graduate students, who are beginning to make contributions by leading evaluations and publications. El Hassar reports an emphasis on the part of Poth to provide her students with realistic work experiences that bridge what they have theoretically learned to what they will need as professional evaluators. One effective strategy that El Hassar describes is connecting new team members with established members so that they can engage in peer learning and mentorship opportunities. In so doing, the impacts of these efforts are anticipated to be seen in the work of future generations of Canadian evaluators.

\section{Foundation for Evaluation Agility}

Planning for agility across evaluation projects contributed to the intern's capacity to adapt the work plan to changing circumstances. As the intern monitored stakeholder needs, the findings reflect evidence of developing evaluative thinking skills (i.e., analyzing and attending to contextual circumstances in which an evaluation occurs) within the domain of situational practice competencies (CES, 2010). Attention to stakeholders' intended use of the findings and process helped the intern learn how to prioritize her tasks and bound her work. Such efforts are aligned with literature pointing to the need for the mentor and coordinator in effective internships to negotiate feasible roles for everyone involved (Yiu \& Law, 2012). Negotiating roles among those involved and supporting the intern in adjusting to the contextual circumstances are important in cross fields (e.g., science and technology, engineering) (Amorin et al., 2012; Eames \& Coll, 2012)

Poth highlights the key role that Dr. Shulha's tutelage played in promoting evaluation use. She recalls having to adapt the work plan (activities and timeframe) for an evaluation to keep pace with the needs of certain stakeholders to use outcomes that were not yet available. Poth remembers discussing this at length with Dr. Shulha and together presenting to the stakeholders a revised plan that met their informational needs. This stimulated Poth's subsequent research interest in developmental evaluation approaches that she continues to implement and contribute to practice (e.g., Poth, 2008; Poth, Pinto, \& Howery, 2012). Specifically, El Hassar refers to Poth's approach to revisit work plans several times over the duration of a project - this was important to build shared understandings of expectations and the work boundaries for the team that could then be further articulated with stakeholders. This was especially evident when responding to changes such as emergent informational needs on the part of the stakeholder or as limitations in the data collected are understood, both of which required renegotiating boundaries and expectations. Such experiences are aligned with literature about building a professional identity as an evaluator. Podems (2014) advances that having evaluator competency lists could potentially limit what we consider to be evaluation practice. Indeed, the literature notes that evaluation is often more art than science, often due to the political nature and specific contexts in which evaluations are undertaken (Patton, 2014; Stake, 2004). 
As our understandings of the role of evaluators in promoting use has evolved, so has attention to the complex environments in which evaluation takes place. Evaluation approaches have emerged with a focus on monitoring and responding to the dynamic influences within these complex environments. Over the last decade, developmental evaluation has become increasingly recognized as a distinct evaluation approach useful for supporting innovations and adaptations within complex environments (Patton, 2010). To position the evaluation process to adapt to the numerous interacting factors and dynamic variables, the evaluator works closely with stakeholders to facilitate opportunities to use evaluation findings and processes.

\section{IMPLICATIONS}

This study advances two implications for informing evaluator induction within the Canadian context. First, internship experiences should be considered an integral part of the process of induction to the evaluation profession. This particular study illustrates the strong potential of internships to play a critical role in meeting the demand for skilled evaluators in government by creating an authentic milieu. Indeed, by responding to changing circumstances and networking with others doing evaluation, the internship provided an opportunity for the intern to experience what an evaluator can expect to encounter in the real world. To that end, the intern demonstrated evidence of having developed certain evaluator competencies as identified in the CES's professional designation program. This study points to the untapped potential of internship experiences (and more generally to evaluator induction) to be guided by a competency-based framework. The CES competencies can provide a means for assessing existing skills, planning and implementing relevant activities, and then providing formative feedback. The timing of this particular internship before formal evaluation coursework reminds us of an important conceptual limitation of this study - the study simply focused on the internship experience and did not take into account the influence of previous exposure to evaluation or subsequent coursework and additional experiences. Indeed, the internship was undertaken before the intern had completed the foundational evaluation course; this was atypical and may account in some instances for her lack of confidence about how to undertake evaluation work. Although the intern had strong skills in quantitative methods, other aspects of undertaking evaluation-specifically collaborating and communicating with stakeholders-had not yet been fully developed or understood by her. The subsequent coursework would likely have emphasized the importance of communication throughout and served to clarify the importance of engaging stakeholders, the importance of collaboration and communication within evaluation work having been well established (CES, 2010). We acknowledge the limited generalizability of our findings and point to the need for further study involving additional interns, mentors, and internships beyond the government context. A necessary future direction would be monitoring implementation of an induction process and the key features across internship experiences and coursework for effective mentoring practices. 
Second, it matters greatly who is involved in the internship experiences, because effective educational experiences require cooperation from all parties about the level of agreement among those involved. This particular study elucidates the internship experience from three perspectives, each of which plays a critical role in the planning, implementation, and assessment of learning outcomes. Even before the internship began, the choices made by the mentor and coordinator and their background experiences and expertise influenced the internship-for example, its duration, expectations, and interactions. At the same, the intern's background expertise and experiences influenced her interactions with, for example, team members, mentor, and coordinator. This leads us to consider an important methodological limitation in this study: the design and subsequent data procedures did not seek to understand the underlying knowledge, skills, or attitudes toward the mentoring practices. Instead we relied on what the participant reported as key features, emergent challenges, and learning outcomes at the end of the internship. This means any attempt to demonstrate a direct correlation between internship experiences and mentoring practices is unreasonable, given the wide variety of possible mediating variables. Indeed, the timing of our interviews following the completion of the internship meant we were relying on recollections of the experience. Further research is needed to (a) address the limited focus on the internship experience within the inductive process and (b) replicate this study across contexts, assessing more diverse methodologies, and integrating a longitudinal study measuring the long-term impacts for greater generalization and understandings of how to go about induction into the evaluation profession. In so doing, the internship experience can become an opportunity for bridging existing interpersonal, reflective, situational, and technical skills to evaluation competencies.

\section{CONCLUSION}

The present study contributes meaningfully to understanding influential mentoring practices important in informing evaluator induction. To begin to address the lack of empirically based quality indicators, the analysis of an internship experience revealed three influential mentoring practices: attention to organizational belonging, promotion of self-sufficiency, and adaptations to changing circumstances. These findings provided the impetus for articulating Dr. Shulha's influence on Canadian evaluation practice in light of the Canadian Evaluation Competencies and her influence on Poth's present mentoring approach in terms of encouraging effective collaborations, engaging in substantial evaluation tasks, and modelling responses to changing contexts. To that end, it matters what experiences are offered and who is involved in the collaborative efforts required for an effective internship.

\section{ACKNOWLEGEMENTS}

The authors wish to acknowledge the contributions of Louise Bahry, Alvin Yapp, Adrienne Montgomerie and Jessica Stowe in the present study and review of the manuscript. 


\section{REFERENCES}

Amorin, M., Pimentel, C., \& Rosa, M. J. (2012). IEM graduates transition to the labour market: the importance of internships. International Journal of Industrial Engineering and Management, 3(2), 83-92.

Brinkmann, S., \& Kvale, S. (2015). InterViews: Learning the craft of qualitative research interviewing (3rd ed.). Thousand Oaks, CA: Sage.

Buchanan, H. (2015). A made-in-Canada credential: Developing an evaluation professional designation. Canadian Journal of Program Evaluation, 29(3), 33-53. http:// dx.doi.org/10.3138/cjpe.29.3.33

Cain, W. (2010). Theories of development: concepts and applications (6th ed.). Upper Saddle River, NJ: Prentice Hall.

Callanan, G., \& Benzing, C. (2004). Assessing the role of internships in the career-oriented employment of graduating college students. Education + Training, 46(2), 82-89. http://dx.doi.org/10.1108/00400910410525261

Canadian Evaluation Society. (2010). Competencies for Canadian evaluation practice. Retrieved from www.evaluationcanada.ca.

Canadian Psychological Association. (2016). Provincial and territorial licensing requirements. Retrieved from http://www.cpa.ca/accreditation/

Cousins, J. B., \& Aubry, T. (2006). Roles for government in evaluation quality assurance: Discussion paper. Ottawa, ON: Treasury Board of Canada, Secretariat and University of Ottawa. Retrieved from www.tbs-sct.gc.ca/eval/

Cousins, J. B., \& Earl, L. M. (1992). The case for participatory evaluation. Educational Evaluation and Policy Analysis, 14(4), 397-418. http://dx.doi.org/10.3102/01623737014004397

Cousins, J. B., Goh, S. C., Aubry, T., Lahey, R., Montague, S., \& Elliott, C. (2006, November). What makes evaluation useful in government? A concept mapping study. Paper presented at the annual meeting of the American Evaluation Association, Portland, OR.

Dillman, L. M. (2013). Evaluator skill acquisition: Linking educational experiences to competencies. American Journal of Evaluation, 34(2), 270-285. http://dx.doi. org/10.1177/1098214012464512

Eames, C., \& Coll, R. K. (2012). Connecting scientists and technologists with students through cooperative education. In B. France \& V. Compton (Eds.), Bringing communities together (pp. 175-185). Rotterdam, Netherlands: Sense Publishers. Retrieved from http://link.springer.com/chapter/10.1007/978-94-6091-791-2_13. http://dx.doi. org/10.1007/978-94-6091-791-2_13

Fierro, L. A., Galport, N., Hunt, A., Codd, H., \& Donaldson, S. I. (2016). Canadian Evaluation Society credentialed evaluator designation program: Evaluation report. Claremont, CA: Claremont Evaluation Center. Retrieved from http://evaluationcanada.ca/ txt/2016_pdp_evalrep_en.pdf

Gault, J., Leach, E., \& Duey, M. (2010). Effects of business internships on job marketability: The employers' perspective. Education + Training, 52(1), 76-88. http://dx.doi. org/10.1108/00400911011017690

Gauthier, B., Barrington, G., Bozzo, S. L., Chaytor, K., Dignard, A., Lahey, R., . . ., \& Roy, S. (2010). The lay of the land: Evaluation practice in Canada in 2009. Canadian Journal of Program Evaluation, 24(1), 1-49. 
Gauthier, B., Barrington, G. V., Bozzo, S. L., Chaytor, K., Cullen, J., Lahey, R., . . , \& Roy, S. (2004). The lay of the land: Evaluation practice in Canada today. Canadian Journal of Program Evaluation, 19(1), 143-178.

Gauthier, B., Kishchuk, N., Borys, S., \& Roy, S. (2006). Evaluation practice in Canada: Results of a national survey. Canadian Journal of Program Evaluation, 21(3), 1-42.

Glaser, B., \& Strauss, A. (1967). The discovery of grounded theory. Chicago, IL: Aldine.

Government of Canada. (2009). Policy on evaluation. Retrieved from www.tbs-sct.gc.ca/ $\mathrm{pol} /$ doc-eng.aspx?id=15024\&section=text.

Government of Canada. (2016). Directive on results. Retrieved from http://www.tbs-sct. gc.ca/pol/doc-eng.aspx?id=31306

Grbich, C. (2013). Qualitative data analysis: An introduction (2nd ed.). London, UK: Sage.

Henry, J. S., Rehwaldt, S. S., \& Vineyard, G. M. (2001). Congruency between student interns and worksite supervisors regarding critical elements of an internship experience. Information Technology, Learning and Performance Journal, 19, 31-41.

Hill, L. A., \& Sawatzky, J.-A. V. (2011). Transitioning into the nurse practitioner role through mentorship. Journal of Professional Nursing, 27(3), 161-167. http://dx.doi. org/10.1016/j.profnurs.2011.02.004

Jacob, S., \& Boisvert, Y. (2010). To be or not to be a profession: Pros, cons and challenges for evaluation. Evaluation, 16(4), 349-369. http://dx.doi.org/10.1177/1356389010380001

King, J. (2007). Making sense of participatory evaluation. In S. Mathison (Ed.), Enduring issues in evaluation: The 20th anniversary of the collaboration between NDE and AEA, New Directions in Evaluation, 114, 83-86.

LaVelle, J. M., \& Donaldson, S. I. (2010). University-based evaluation training programs in the United States 1980-2008: An empirical examination. American Journal of Evaluation, 31(1), 9-23. http://dx.doi.org/10.1177/1098214009356022

LaVelle, J. M., \& Donaldson, S. I. (2015). The state of preparing evaluators. In J. W. Altshuld and M. Engle (Eds.), Accreditation, certification, and credentialing: Relevant concerns for U. S. evaluators. New Directions for Evaluation, 145, 39-52.

Marshall, C., \& Rossman, G. B. (2015). Designing qualitative research (6th ed.). Thousand Oaks, CA: Sage.

O'Sullivan, R. (2012). Collaborative evaluation within a framework of stakeholder-oriented evaluation approaches. Evaluation and Program Planning, 35(4), 518-522. http:// dx.doi.org/10.1016/j.evalprogplan.2011.12.005

Patton, M. Q. (2010). Developmental evaluation: Applying complexity concepts to enhance innovation and use. New York, NY: Guilford Press.

Patton, M. Q. (2014). Utilization-focused evaluation (4th ed.). Thousand Oaks, CA: Sage.

Patton, M. Q. (2015). Qualitative evaluation and research methods (4th ed.). Thousand Oaks, CA: Sage.

Picciotto, R. (2011). The logic of evaluation professionalism. Evaluation, 17(2), 165-180. http://dx.doi.org/10.1177/1356389011403362

Podems, D. (2014). Evaluator competencies and professionalizing the field: Where are we now? Canadian Journal of Program Evaluation, 28, 127-136. 
Poth, C. (2008). Promoting evaluation use within dynamic organizations: A case study examining evaluator behaviour (Unpublished dissertation). Queen's University, Kingston, ON.

Poth, C., Lamarche, M., Yapp, A., Sulla, E., \& Chisamore, B. (2014). Toward a new definition of evaluation within the Canadian context: Who knew this would be so difficult? Canadian Journal of Program Evaluation, 29(1), 97-103. http://dx.doi.org/10.3138/ cjpe.29.1.87

Poth, C., Pinto, D., \& Howery, K. (2012). Addressing the challenges encountered during a developmental evaluation: Implications for evaluation practice. Canadian Journal of Program Evaluation, 26(1), 39-48.

Poth, C., \& Shulha, L. M. (2008). Encouraging stakeholder engagement: A case study of evaluator behavior. Studies in Educational Evaluation, 34(4), 218-223. http://dx.doi. org/10.1016/j.stueduc.2008.10.006

Rog, D. J. (2015). Infusing theory into practice, practice into theory: Small wins and big gains for evaluation. American Journal of Evaluation, 36(2), 223-238. http://dx.doi. org/10.1177/1098214015573068

Schwartz, R., \& Mayne, J. (2005). Assuring the quality of evaluative information: Theory and practice. Evaluation and Program Planning, 28(1), 1-14. http://dx.doi.org/10.1016/j. evalprogplan.2004.10.001

Shulha, L. M., Whitmore, E., Cousins, J. B., Gilbert, N., \& al Hudib, H. (2016). Introducing evidence-based principles to guide collaborative approaches to evaluation: Results of an empirical process. American Journal of Evaluation, 37(2), 193-215. http://dx.doi. org/10.1177/1098214015615230

Shulha, L. M., \& Wilson, R. J. (2003). Collaborative mixed methods research. In A. Tashakkori \& C. Teddlie (Eds.), Handbook of mixed methods in social \& behavioral research (pp. 639-670). Thousand Oaks, CA: Sage.

Stake, R. (2004). Standards based and responsive evaluation. Thousand Oaks, Ca: Sage.

Thune, T., \& Støren, L. A. (2015). Study and labour market effects of graduate students' interaction with work organisations during education: A cohort study. Education + Training, 57(7), 702-722. http://dx.doi.org/10.1108/ET-10-2014-0126

Van Melle, E., Cimellaro, L., \& Shulha, L. (2003). A dynamic framework to guide the implementation and evaluation of educational technologies. Education and Information Technologies, 8, 267-285.

Wilcox, Y., \& King, J. (2014). A professional grounding and history of the development and formal use of evaluator competencies. Canadian Journal of Program Evaluation, 28(3), 1-28.

Yiu, M., \& Law, R. (2012). A review of hospitality internship: Different perspectives of students, employers, and educators. Journal of Teaching in Travel \& Tourism, 12(4), 377-402. http://dx.doi.org/10.1080/15313220.2012.729459

\section{AUTHOR INFORMATION}

Cheryl Poth, Ph.D., is an associate professor in the Centre for Applied Measurement and Evaluation within the Department of Educational Psychology, Faculty of Education, 
University of Alberta, and a co-founder of the Alberta Clinical and Community-based Evaluation Research Team. She teaches and conducts research on program evaluation working with stakeholders from school boards, postsecondary institutions, and federal organizations in the areas of educational programs and health services. She is a regular contributor to the Canadian and American Evaluation Association conferences and publications. Her research interests include evaluation use with particular emphasis on developmental evaluation.

Michelle Anderson-Draper was the former Manager of Strategic Evaluation for Alberta Children and Youth Services (2008-2011). She holds a Master of Arts from the University of Ottawa and a Master of Science from the University of Alberta. She was among the first group of applicants to receive the Canadian Evaluation Society's professional designation of credentialed evaluation in February 2011. She is a partner with AndersonDraper Consulting.

Btissam El Hassar is a doctoral candidate in the Department of Educational Psychology at the University of Alberta. Her research interests include empirically studying the theory and practice of evaluation and evaluation capacity building. Under the supervision of Dr. Cheryl Poth, her dissertation focused on creating and validating an evaluation capacity building instrument using a mixed methods approach. She is a member of the Alberta Clinical and Community-based Evaluation Research Team. Btissam holds a Master of Public Policy from the University of Maryland, US. 